Short communication

\title{
First aromatic ring acetamidation by anodic oxidation
}

\author{
Fructuoso Barba $^{\mathrm{a}, *}$, Isidoro Barba ${ }^{\mathrm{b}}$, Belen Batanero ${ }^{\mathrm{a}}$ \\ a Department of Organic Chemistry, University of Alcala, 28871 Alcala de Henares, Madrid, Spain \\ b Department of Organic Chemistry, University of Alicante, Ap. 99, 03080 Alicante, Spain
}

\section{A R T I C L E I N F O}

Article history:

Received 24 July 2014

Received in revised form 25 August 2014

Accepted 27 August 2014

Available online 6 September 2014

\section{Keywords:}

Acetanilides

Anode

1-(Trifluoromethyl)benzene

Acetonitrile/ $/ \mathrm{Bu}_{4} \mathrm{NBF}_{4}$

Potentiostatic conditions

\begin{abstract}
A B S T R A C T
Anodic oxidation of 1-(trifluoromethyl)benzene in dry acetonitrile/ $\mathrm{Bu}_{4} \mathrm{NBF}_{4}$ under constant potential conditions led to 2-(trifluoromethyl) acetanilide in $86 \%$ yield. Other experimental conditions, as the use of constant current or the change in the supporting electrolyte were considered.
\end{abstract}

(c) 2014 Elsevier B.V. All rights reserved.

\section{Introduction}

Trifluoromethylated arenes are important motifs in many pharmaceuticals, agrochemicals and organic materials due to the strong electron-withdrawing nature and the large hydrophobic domain of a $\mathrm{CF}_{3}$-group [1,2].

The interest of acetamidated 1-(trifluoromethyl)benzene deals notably with the utility of the acetamido group providing other opportunities to transform it into different functional groups, opening new access to many synthetic therapeutic agents $[1,3,4]$.

Conventional preparations of these acetamidated 1-(trifluoromethyl) benzenes have been recently described, as the $\mathrm{Pd}(\mathrm{II})$-catalyzed trifluoromethylation of the aromatic $\mathrm{C}-\mathrm{H}$ bond in acetanilides, which provides the highly biological potential key structure of ortho- $\mathrm{CF}_{3}$ acetanilides [5] or the ortho-trifluoromethylation of $\mathrm{N}$-aryl-benzamide catalyzed by Pd using the Umemoto reagent as the $\mathrm{CF}_{3}$ source [6]. Direct Cu-catalyzed trifluoromethylation of pivalamido arenes with Togni reagent takes place with high selectivity at the ortho-position [7].

On the other hand, the metabolism of 2-trifluoromethylacetanilide in the rat has been determined [8].

The electrochemical acetamidation reaction of alkyl aromatic compounds (arenes) was studied in depth by Eberson et al. [9] in acetonitrile/alkaline perchlorate at a platinum anode. The accepted mechanistic proposal [10] is the aromatic ring oxidation in a $2 \mathrm{e}-$-substrate molecule process, followed by a Ritter-type reaction with further

\footnotetext{
* Corresponding author at: The Department of Organic Chemistry of the University of Alcala, Facultad de Farmacia, Campus Universitario, 28871 Alcala de Henares, Madrid, Spain. Tel.: + 34 918854617; fax:+34918854686.

E-mail address: fructuoso.barba@uah.es (F. Barba).
}

hydrolysis of the generated cation during the work-up, to produce the corresponding side-chain acetamide, as indicated in Scheme 1.

As far as we know aromatic ring anodic acetamidation has never been achieved; once the anodic discharge was displayed, the target of acetonitrile has been always the side aliphatic chain. In 2008 and 2011, Kumar et al. [11] published two articles describing the electrochemical ring acetamidation of aromatic compounds using a $0.1 \mathrm{M}$ solution of starting material in acetonitrile $(25 \mathrm{~mL}) /$ water $(25 \mathrm{~mL}) / \mathrm{KCl} 0.1 \mathrm{M}$ as a solvent and supporting electrolyte (SSE). We have tried to reproduce these results, under their experimental conditions, with acetophenone [11a] and p-xylene [11b] as substrates. We have not observed any acetamidation of acetophenone. Instead, the expected benzoic acid was obtained as the main product. In the case of p-xylene, these authors reported a 97\% yield of 2,5-dimethyl acetanilide. In this case we have found some aliphatic acetamidation but none of the mentioned aromatic acetamidation.

In the present communication we describe for the first time an aromatic acetamidation reaction at the electrode.

\section{Experimental section}

The electrolyses were carried out using an Amel potentiostat Model 552 with electronic integrator Amel Model 721. Mass spectra (EI, ionizing voltage $70 \mathrm{eV}$ ) were determined using a THERMOFISHER ITQ-900 DIP/GC-MSn mass-selective detector. IR spectra of the compounds were recorded as dispersions in $\mathrm{KBr}$ or $\mathrm{NaCl}$ films on a Perkin-Elmer FT-IR spectrometer Spectrum 2000. ${ }^{1} \mathrm{H}$ and ${ }^{13} \mathrm{C}$ NMR spectra were recorded in $\mathrm{CDCl}_{3}$ on Varian Unity $300(300 \mathrm{MHz})$ spectrometer with tetramethylsilane (TMS) as the internal standard. The chemical shifts 


$$
\begin{aligned}
& \mathrm{Ar}-\mathrm{CH}_{3} \stackrel{-\mathrm{e}-}{\longrightarrow} \mathrm{Ar}-\mathrm{CH}_{3}{ }^{\cdot+} \stackrel{-\mathrm{H}^{+}}{\longrightarrow} \mathrm{Ar}-\mathrm{CH}_{2} \\
& \mathrm{Ar}-\mathrm{CH}_{2} \stackrel{-\mathrm{e}-}{\longrightarrow} \mathrm{Ar}-\mathrm{CH}_{2} \stackrel{\oplus}{\longrightarrow} \stackrel{\mathrm{CH}_{3} \mathrm{CN}}{\longrightarrow} \mathrm{Ar}-\mathrm{CH}_{2}-\mathrm{N}=\stackrel{\oplus}{\mathrm{C}}-\mathrm{CH}_{3} \\
& \downarrow \begin{array}{l}
\mathrm{H}_{2} \mathrm{O} \\
\text { workup }
\end{array} \\
& \mathrm{Ar}-\mathrm{CH}_{2}-\mathrm{NH}-\mathrm{C}-\mathrm{CH}_{3}
\end{aligned}
$$

Scheme 1. Accepted mechanistic proposal in the electrochemical arene acetamidation.

are given in ppm. Melting points were measured on a Reichert Thermovar microhot stage apparatus and are uncorrected.

\subsection{General electrochemical procedure}

1-(Trifluoromethyl)benzene (1) $\left(5.10^{-3} \mathrm{~mol}, 0.73 \mathrm{~g}\right)$ was dissolved in $60 \mathrm{~mL} \mathrm{SSE}$ : anhydrous acetonitrile/ $\mathrm{Bu}_{4} \mathrm{NBF}_{4}(0.05 \mathrm{M})$ and electrolyzed in a concentric and divided cell (glass-frit D4-diaphragm) equipped with a magnetic stirrer under constant potential conditions $\left(+2.8 \mathrm{~V}\right.$, vs $\mathrm{Ag} / \mathrm{AgCl}$ (sat)) at temperature of $18{ }^{\circ} \mathrm{C}$ maintained constant with a cryostat. A platinum plate $\left(10 \mathrm{~cm}^{2}\right)$ was used as working and counter electrode and a $\mathrm{Ag} / \mathrm{AgCl}$ (sat) electrode as the reference.

Once the reaction was finished, the solvent in the anodic solution was removed under reduced pressure. The residue was extracted with ether/water and the organic phase dried over $\mathrm{Na}_{2} \mathrm{SO}_{4}$ and concentrated by evaporation. The resulting solid was chromatographed on silica gel 60 (35-70 mesh) in a $(22 \times 3 \mathrm{~cm})$ column, using $\mathrm{CH}_{2} \mathrm{Cl}_{2}$ : $\mathrm{EtOH}(20: 1)$ as eluent. Spectroscopic data of the obtained compounds are given below.

2-(Trifluoromethyl)acetanilide (2): (870 mg, 86\% yield). Mp $96{ }^{\circ} \mathrm{C}$. [Lit. [12] $96-96.5{ }^{\circ} \mathrm{C}$ ]. $\operatorname{IR}(\mathrm{KBr}) v=3286,3037,2962$, 1674, 1531, 1320, 1125, 1036, $764 \mathrm{~cm}^{-1}$. ${ }^{1} \mathrm{H}$ NMR $(300 \mathrm{MHz}$, $\left.\mathrm{CDCl}_{3}\right) \delta: 2.15(\mathrm{~s}, 3 \mathrm{H}), 7.16(\mathrm{t}, 1 \mathrm{H}, \mathrm{J}=7.5 \mathrm{~Hz}), 7.36(\mathrm{bs}, 1 \mathrm{H}), 7.49$ $(\mathrm{t}, 1 \mathrm{H}, \mathrm{J}=7.8 \mathrm{~Hz}), 7.54(\mathrm{~d}, 1 \mathrm{H}, \mathrm{J}=7.5 \mathrm{~Hz}), 8.08(\mathrm{~d}, 1 \mathrm{H}, \mathrm{J}=$

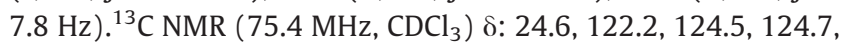
$125.8,126.0,132.8,135.1,168.4$. MS m/e (relative intensity) EI: 203( $\left.\mathrm{M}^{+}, 18\right), 184\left(\mathrm{M}^{+}-19,3\right), 161(98), 141(100), 114(46)$, 75(5), 63(9).

3-(Trifluoromethyl)acetanilide: Mp $102{ }^{\circ} \mathrm{C}$. [Lit. [13] 100-102 ${ }^{\circ} \mathrm{C}$ ]. MS m/e (relative intensity) EI: 203( $\left.\mathrm{M}^{+}, 17\right), 184\left(\mathrm{M}^{+}-19,9\right)$, 161(100), 142(10), 114(12), 63(9).

\section{Results and discussion}

When 1-(trifluoromethyl)benzene (1) was exposed to the experimental oxidative conditions described above, using acetonitrile as the solvent (it means with a weak nucleophile), it was transformed into the corresponding 2-(trifluoromethyl)acetanilide $(\mathbf{2})$ in very good yield.

The reason why the alkyl aromatic derivatives afford the side chain acetamidation reaction, instead of the ring acetamidation (see Scheme 1), is that the initially electrogenerated cation radical at the ring, due to the weak nucleophilic character of acetonitrile, loses an aliphatic proton to produce the more stable benzyl radical that is further oxidized to the cation and subsequently attacked by the acetonitrile through a Ritter-type reaction.
However, when anodic acetoxylation is performed, substitution at the aromatic ring or at the aliphatic side chain can occur depending on the SSE employed. The use of weak nucleophile solvent-supporting electrolyte systems such as $\mathrm{HOAc} / \mathrm{NaClO}_{4}$ drives the reaction to the aliphatic acetate [14], however when the SSE contains a stronger nucleophile: $\mathrm{HOAc} / \mathrm{NaOAc}$ the obtained product is the arylacetate [15] because once the aromatic cation radical is formed the acetate as nucleophile attacks the ring before any side chain proton is evolved.

The preparative-scaled electrolysis of (1), when carried out under our best experimental conditions, allowed getting the aromatic ring acetamidation product (2), after a charge consumption corresponding to a theoretical $2 \mathrm{e}-$ /substrate molecule process. Once finished and further elaborated (2) was obtained in $86 \%$ yield together with a $10 \%$ mixture of 3-(trifluoromethyl)acetanilide and 4-(trifluoromethyl) acetanilide in a 3:1 respectively relationship determined by GC and ${ }^{1} \mathrm{H}-\mathrm{NMR}$.

Concerning the mechanism proposal that explains the formation of (2), it is sumarized in Scheme 2.

After the first electron transfer to the anode, the cation radical cannot be further stabilized by lose of a fluorine cation, as in the case of alkyl aromatic substrates that evolve, as already Eberson described, leaving a proton. Now the Ritter-type reaction with the solvent, acetonitrile, takes place at the ring.

The 2-(trifluoromethyl)acetanilide (2) is the major isomer because the strong withdrawing inductive effect of the trifluoromethyl substituent makes charge deficient the adjacent positions, more easily to be attacked by nucleophiles.

It is important to notice that the best results were obtained using $\mathrm{Bu}_{4} \mathrm{NBF}_{4}$ as electrolyte. When it was substituted by $\mathrm{LiClO}_{4}$, under the applied potential conditions, aromatic chlorinated products were obtained and the reaction was dirty.

When the electrolysis was performed under constant current conditions ( $300 \mathrm{~mA}$ applied during $1 \mathrm{~h}$ ) while maintaining identical the rest of the reaction parameters, the yield of 2-trifluoroacetanilide was $54 \%$. This lower yield is due to the competing formation of some monoacetamide dimers through coupling of the trifluoromethyl benzene cation radical, in addition to the 3- and 4-trifluoroacetanilide isomers.

\section{Conclusions}

The anodic discharge of (trifluoromethyl)benzene under constant potential conditions of $+2.8 \mathrm{~V}$ ( $\mathrm{vs} \mathrm{Ag} / \mathrm{AgCl}$ (sat)) and acetonitrile/ $\mathrm{Bu}_{4} \mathrm{NBF}_{4}$ as SSE, provides the first example of high yielded aromatic ring acetamidation.

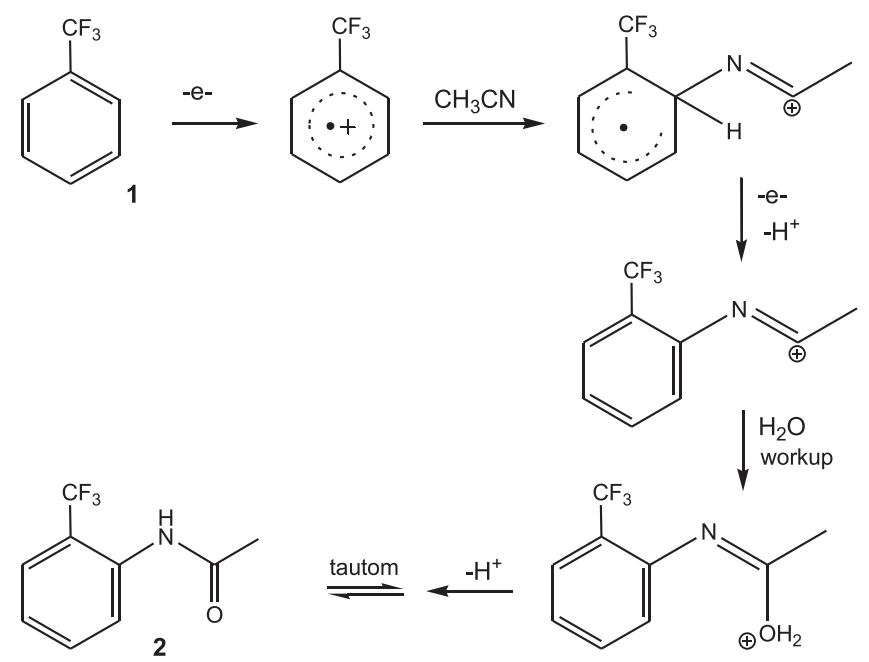

Scheme 2. Aromatic ring acetamidation mechanism. 
The methodology described herein to get trifluoromethylated acetanilides could be easily scaled up under constant current conditions and opens a new access to biological and therapeutic agents.

\section{Conflict of interest}

The authors declare no conflict of interest.

\section{Acknowledgments}

This work was supported by the Spanish Ministry of Science and Education through B. Batanero I3 program the financial support.
[4] K. Muller, C. Faeh, F. Diederich, Science 317 (2007) 1881-1886.

[5] L.-S. Zhang, K. Chen, G. Chen, B.-J. Li, S. Luo, Q.-Y. Guo, J.-B. Wei, Z.-J. Shi, Org. Lett. 15 (2013) 10-13.

[6] X.-G. Zhang, H.-X. Dai, M. Wasa, J.-Q. Yu, J. Am. Chem. Soc. 134 (2012) 11948-11951.

[7] S. Cai, Ch. Chen, Z. Sun, Ch. Xi, Chem. Commun. 49 (2013) 4552-4554.

[8] M. Tugnait, E.M. Lenz, M. Hofmann, M. Spraul, I.D. Wilson, J.C. Lindon, J.K. Nicholson, J. Pharm. Biomed. Anal. 30 (2003) 1561-1574.

[9] L. Eberson, K. Nyberg, Tetrahedron Lett. (1966) 2389-2393.

[10] L. Eberson, B. Olofson, Acta Chem. Scand. 23 (1969) 2355-2366.

[11] a) L.K. Sharma, S. Kumar, P. Yadav, R.K.P. Singh, Ind. J. Chem. Sect. B 47 (2008) 1277-1280;

b) S. Kumar, S. Singh, R.K.P. Singh, J. Indian Chem. Soc. 88 (2011) 1041-1045.

[12] M.J. Fifolt, J. Org. Chem. 50 (1985) 4576-4582.

[13] F. Shi, Org. Lett. 8 (2006) 1411-1414.

[14] L. Eberson, J. Am. Chem. Soc. 89 (1967) 4669-4677.

[15] L. Eberson, K. Nyberg, J. Am. Chem. Soc. 88 (1966) 1686-1691.

\section{References}

[1] M. Schlosser, Angew. Chem. Int. Ed. 45 (2006) 5432-5446.

[2] T. Furuya, A.S. Kamlet, T. Ritter, Nature 473 (2011) 470-477.

[3] W.K. Hagmann, J. Med. Chem. 51 (2008) 4359-4369. 